\title{
BMJ Open Sociodemographic inequality in COVID-19 vaccination coverage among elderly adults in England: a national linked data study
}

\author{
Vahe Nafilyan (D) , ${ }^{1,2}$ Ted Dolby, ${ }^{1}$ Cameron Razieh, ${ }^{3,4,5}$ \\ Charlotte Hannah Gaughan (1) , ${ }^{6}$ Jasper Morgan, ${ }^{1}$ Daniel Ayoubkhani, ${ }^{6}$ \\ Sarah Walker, ${ }^{7}$ Kamlesh Khunti, ${ }^{3,4,5}$ Myer Glickman, ${ }^{1}$ Thomas Yates ${ }^{3,4,5}$
}

To cite: Nafilyan V,

Dolby T, Razieh C, et al. Sociodemographic inequality in COVID-19 vaccination coverage among elderly adults in England: a national linked data study. BMJ Open 2021;11:e053402. doi:10.1136/ bmjopen-2021-053402

- Prepublication history for this paper is available online. To view these files, please visit the journal online (http://dx.doi. org/10.1136/bmjopen-2021 053402).

Received 13 May 2021 Accepted 12 July 2021
Check for updates

(C) Author(s) (or their employer(s)) 2021. Re-use permitted under CC BY. Published by BMJ.

For numbered affiliations see end of article.

Correspondence to Dr Vahe Nafilyan; vahe.nafilyan@ons.gov.uk

\section{ABSTRACT}

Objective To examine inequalities in COVID-19 vaccination rates among elderly adults in England. Design Cohort study.

Setting People living in private households and communal establishments in England.

Participants 6655672 adults aged $\geq 70$ years (mean 78.8 years, $55.2 \%$ women) who were alive on 15 March 2021.

Main outcome measures Having received the first dose of a vaccine against COVID-19 by 15 March 2021. We calculated vaccination rates and estimated unadjusted and adjusted ORs using logistic regression models.

Results By 15 March 2021, 93.2\% of people living in England aged 70 years and over had received at least one dose of a COVID-19 vaccine. While vaccination rates differed across all factors considered apart from sex, the greatest disparities were seen between ethnic and religious groups. The lowest rates were in people of black African and black Caribbean ethnic backgrounds, where only $67.2 \%$ and $73.8 \%$ had received a vaccine, with adjusted odds of not being vaccinated at $5.01(95 \% \mathrm{Cl}$ 4.86 to 5.16 ) and 4.85 (4.75 to 4.96 ) times greater than the white British group. The proportion of individuals selfidentifying as Muslim and Buddhist who had received a vaccine was $79.1 \%$ and $84.1 \%$, respectively. Older age, greater area deprivation, less advantaged socioeconomic position (proxied by living in a rented home), being disabled and living either alone or in a multigenerational household were also associated with higher odds of not having received the vaccine.

Conclusion Research is now urgently needed to understand why disparities exist in these groups and how they can best be addressed through public health policy and community engagement.

\section{INTRODUCTION}

The UK began an ambitious vaccination programme to combat the COVID-19 pandemic on 8 December 2020; by 24 April 2021, $64 \%$ of the UK adult population have received their first of the dose. ${ }^{1}$
Strengths and limitations of this study

- The main strength of our population-level dataset is the availability of a wide range of sociodemographic characteristics not included in electronic health records, allowing for a detailed examination of inequalities in vaccination coverage.

- We presented vaccination rates and Odds Ratios for non-vaccination adjusted for a range of factors to understand further inequalities in vaccination coverage.

- The main limitation is that most demographic and socioeconomic characteristics were derived from the 2011 Census and therefore are 10 years old.

- Because the dataset is based on the 2011 Census, it excluded people living in England in 2011 but not taking part in the 2011 Census, respondents who could not be linked to the 2011-2013 National Health Service Patient Register and recent migrants.

Previous research demonstrates that vaccination rates tend to be lower among certain ethnic groups, and in areas of higher deprivation. $^{2-4}$ Existing evidence suggests that COVID-19 vaccination rates differ by level of area deprivation, certain underlying health conditions and ethnicity. ${ }^{5}$ Far less is known about how COVID-19 vaccination uptake varies by sociodemographic factors, such as religious affiliation, individual socioeconomic status, living in multigenerational household or disability status, factors disproportionately associated with SARS-CoV-2 infection. Understanding which sociodemographic, economic and cultural factors are associated with low vaccination rates has major implications for designing policies that help maximise the vaccination campaign coverage.

This study investigates inequality in vaccination rates among adults aged $\geq 70$ years in England, using population-level 
Table 1 Variables used in the analyses

\begin{tabular}{|c|c|c|}
\hline Variable & Coding & Source \\
\hline Vaccinated & Received a first dose of a COVID-19 vaccine by 15 March 2020 & NIMS \\
\hline Age & Third-order polynomial & 2011 Census \\
\hline Ethnicity & $\begin{array}{l}\text { White British, Bangladeshi, Black African, Black Caribbean, Chinese, Indian, } \\
\text { Mixed, Other, Pakistani, White other }\end{array}$ & 2011 Census \\
\hline Region & Dummy variables representing region of residence & $\begin{array}{l}2019 \text { NHS Patient } \\
\text { Register }\end{array}$ \\
\hline Rural-urban classification & Urban, rural & $\begin{array}{l}2019 \text { NHS Patient } \\
\text { Register }\end{array}$ \\
\hline Index of Multiple Deprivation & Dummy variables representing quintiles of deprivation & $\begin{array}{l}2019 \text { NHS Patient } \\
\text { Register }\end{array}$ \\
\hline Disability & Non-disabled, disabled (limited a little), disabled (limited a lot) & 2011 Census \\
\hline Body mass index $\left(\mathrm{kg} / \mathrm{m}^{2}\right)$ & $<18.5,18.5-25,25-30, \geq 30$, missing & GPES \\
\hline Chronic kidney disease (CKD) & No CKD, CKD3, CKD4, CKD5 & GPES \\
\hline Learning disability & No learning disability, Down's syndrome, other learning disability & GPES \\
\hline Cancer and immunosuppression & $\begin{array}{l}\text { Dummies for blood cancer, solid organ transplant, prescribed } \\
\text { immunosuppressant medication by GP, prescribed leukotriene or long-acting } \\
\text { beta blockers, prescribed regular prednisolone }\end{array}$ & GPES \\
\hline Other conditions & $\begin{array}{l}\text { Diabetes, chronic obstructive pulmonary disease, asthma, rare pulmonary } \\
\text { diseases, pulmonary hypertension or pulmonary fibrosis, coronary heart } \\
\text { disease, stroke, atrial fibrillation, congestive cardiac failure, venous } \\
\text { thromboembolism, peripheral vascular disease, congenital heart disease, } \\
\text { dementia, Parkinson's disease, epilepsy, rare neurological conditions, } \\
\text { cerebral palsy, severe mental illness (bipolar disorder, schizophrenia, severe } \\
\text { depression), osteoporotic fracture, rheumatoid arthritis or systemic lupus } \\
\text { erythematosus, cirrhosis of the liver }\end{array}$ & GPES/HES \\
\hline
\end{tabular}

GCSE, General Certificate of Secondary Education; GP, general practitioner; GPES, General Practice Extraction Service; HES, Hospital Episode Statistics; NHS, National Health Service; NIMS, National Immunisation Management System.

administrative records linked to the 2011 Census. This enables examination of a wide range of sociodemographic characteristics, currently lacking in previously published studies, in particular ethnicity, religion, different measures of socioeconomic position and those who report being disabled.

\section{METHODS}

\section{Study data}

We linked vaccination data from the National Immunisation Management System (NIMS) to the Office for National Statistics (ONS) Public Health Data Asset (PHDA) based on National Health Service (NHS) number. The ONS PHDA is a linked dataset combining the 2011 Census, mortality records, the General Practice Extraction Service data for pandemic planning and research and the Hospital Episode Statistics. To obtain NHS numbers for the 2011 Census, we linked the 2011 Census to the 2011-2013 NHS Patient
Registers using deterministic and probabilistic matching, with an overall linkage rate of $94.6 \%$. All subsequent linkages were performed based on NHS numbers.

The study population consisted of people aged $\geq 70$ years, alive on 15 March 2020, who were residents in England, registered with a general practitioner and enumerated at the 2011 Census. Of 6605315 adults aged $\geq 70$ years who received a first dose of a COVID-19 vaccine in NIMS, 6242384 (94.5\%) were linked to the ONS PHDA.

\section{Outcome}

The main outcome was having received at least a first dose of a COVID-19 vaccine by 15 March 2021, as recorded in the NIMS data available on 31 March 2021. Phase 1 of the vaccination policy for England aimed to offer a first vaccination appointment to all those $\geq 70$ years by 15 February, and we allowed a further month to ensure full coverage. 


\begin{tabular}{|c|c|c|}
\hline Variable & Level & Count (\%) \\
\hline Vaccinated & & 6202780 (93.2) \\
\hline \multirow[t]{2}{*}{ Sex } & Female & 3672314 (55.2) \\
\hline & Male & $2983358(44.8)$ \\
\hline Age & Mean (SD) & $78.8(6.5)$ \\
\hline \multirow[t]{10}{*}{ Ethnicity } & Bangladeshi & $11522(0.2)$ \\
\hline & Black African & $21535(0.3)$ \\
\hline & Black Caribbean & $52883(0.78)$ \\
\hline & Chinese & $18452(0.38)$ \\
\hline & Indian & $103564(1.6)$ \\
\hline & Mixed & $24637(0.34)$ \\
\hline & Other & $65241(1.0)$ \\
\hline & Pakistani & $39723(0.6)$ \\
\hline & White British & 6095276 (91.6) \\
\hline & White other & 222839 (3.4) \\
\hline \multirow[t]{9}{*}{ Religion } & Buddhist & $16403(0.3)$ \\
\hline & Christian & $5221392(78.5)$ \\
\hline & Hindu & $61634(0.9)$ \\
\hline & Jewish & $39800(0.6)$ \\
\hline & Muslim & $86841(1.3)$ \\
\hline & No religion & 725695 (10.9) \\
\hline & Other religion & $22327(0.3)$ \\
\hline & Religion not stated & 449781 (6.8) \\
\hline & Sikh & $31799(0.5)$ \\
\hline \multirow[t]{5}{*}{ IMD quintile } & 1 (most deprived) & $913809(13.7)$ \\
\hline & 2 & 1140651 (17.1) \\
\hline & 3 & $1407155(21.1)$ \\
\hline & 4 & $1560023(23.4)$ \\
\hline & 5 (least deprived) & $1634034(24.6)$ \\
\hline \multirow[t]{4}{*}{ Household tenure } & Owned & $5488126(82.5)$ \\
\hline & Private rented & 273707 (4.1) \\
\hline & Social rented & 778867 (11.7) \\
\hline & $\begin{array}{l}\text { Other (eg, } \\
\text { live rent free) }\end{array}$ & $114972(1.7)$ \\
\hline \multirow[t]{2}{*}{ Rural-urban } & Rural & $6005144(82.4)$ \\
\hline & Urban & 304412 (4.2) \\
\hline \multirow{6}{*}{$\begin{array}{l}\text { Household } \\
\text { composition }\end{array}$} & 2 elderly & 847508 (11.6) \\
\hline & 1 elderly & $128083(1.8)$ \\
\hline & $\begin{array}{l}\text { Care } \\
\text { home }\end{array}$ & 436211 (6.0.) \\
\hline & $\begin{array}{l}\text { Missing } \\
\text { household }\end{array}$ & $9035(0.1)$ \\
\hline & Multigenerational & 620167 (8.5) \\
\hline & $\begin{array}{l}\text { Other } \\
\text { (3+ adults) }\end{array}$ & $714211(9.8)$ \\
\hline
\end{tabular}

Adults aged 70 years or over, living in England, alive on 15 March 2021.

IMD, Index of Multiple Deprivation.

\section{Exposures and covariates}

This dataset combines comprehensive sociodemographic information from the 2011 Census with a detailed medical history from clinical records. All individual-level sociodemographic characteristics (ethnic group, religious affiliation, disability status, educational attainment) came from the 2011 Census. We used a 10-category ethnic group classification (White British, Bangladeshi, Black African, Black Caribbean, Chinese, Indian, Mixed, Other, Pakistani, White other). Self-reported religious group, place of residence (region within England, private or care home) and area-based deprivation (Index of Multiple Deprivation $^{6}$ ) were derived based on the 2019 Patient Register. Comorbidities were defined as in the QCovid risk prediction model, a model used to assess the risk of severe COVID-19 outcomes in the general population, used to inform the prioritisation of the vaccination campaign. ${ }^{7}$ All variables included in this analysis are listed in table 1.

\section{Statistical analyses}

First, we estimated the first dose vaccination rates by a range of demographic and socioeconomic characteristics. Second, to understand the drivers of the observed differences in vaccination rates, we used logistic regression to estimate the odds of not having received a first dose of a COVID-19 vaccine. For each exposure, we compared ORs from models adjusted for different sets of covariates. We estimated unadjusted ORs, ORs adjusted for sex and age, and ORs adjusted for all geographical and sociodemographic characteristics, disability status and pre-existing conditions. All analyses were conducted using R V.3.5

\section{Patient and public involvement \\ No patient involved.}

\section{RESULTS}

Our study population included 6655672 adults aged $\geq 70$ years who lived in England. A total of $55.2 \%$ were women and the mean age was 78.8 (SD: 6.5) years; $91.6 \%$ identified themselves as White British, $78.5 \%$ as Christian. A total of $82.5 \%$ owned their home (table 2). By 15 March 2021, 93.2\% of people living in England aged 70 years and over had received at least one dose of a COVID-19 vaccine.

Table 3 shows vaccination rates by demographic and socioeconomic factors, as well as ORs from different models. Vaccination rates differed across all factors considered, apart from sex. The lowest rates were in people of Black African and Black Caribbean ethnic backgrounds where only $67.2 \%$ and $73.9 \%$ had received a vaccine. Adjusting for differences in geography, sociodemographic factors and underlying health conditions did not fully explain the lower probability of having received the vaccine among ethnic minority groups. Compared with people of white British ethnicity, the fully adjusted OR for Black African individuals was 5.01 (95\% CI 4.86 to 5.16), while the unadjusted OR was 7.62 (7.40 to 7.84), 
Table 3 Vaccination rates and ORs for not being vaccinated by sociodemographic characteristics

\begin{tabular}{|c|c|c|c|c|c|}
\hline Exposure & Group & Vaccination rate & OR (model 1) & OR (model 2) & OR (model 3) \\
\hline \multirow[t]{5}{*}{ Age group } & $70-74$ & 90.9 (90.8 to 90.9$)$ & 1 (ref) & 1 (ref) & 1 (ref) \\
\hline & $75-79$ & 93.8 (93.8 to 93.9$)$ & 0.65 (0.65 to 0.66$)$ & $0.65(0.65$ to 0.66$)$ & 0.66 (0.65 to 0.66$)$ \\
\hline & $85-89$ & 95.1 (95.0 to 95.1$)$ & 0.51 (0.51 to 0.52) & $0.51(0.51$ to 0.52$)$ & 0.51 (0.51 to 0.52$)$ \\
\hline & $90-94$ & 94.0 (93.9 to 94.1$)$ & 0.63 (0.62 to 0.64$)$ & $0.63(0.62$ to 0.64$)$ & 0.64 (0.63 to 0.65$)$ \\
\hline & $100+$ & 85.5 (84.8 to 86.1$)$ & 1.69 (1.61 to 1.78$)$ & $1.68(1.60$ to 1.77$)$ & $1.60(1.52$ to 1.68$)$ \\
\hline \multirow[t]{2}{*}{ Sex } & Female & 93.2 (93.2 to 93.2) & 1 (ref) & 1 (ref) & 1 (ref) \\
\hline & Male & 93.2 (93.2 to 93.2) & 1.00 (1.00 to 1.01$)$ & 0.98 (0.98 to 0.99$)$ & 1.03 (1.02 to 1.03$)$ \\
\hline \multirow[t]{2}{*}{ Disability } & Not limited & 93.5 (93.5 to 93.5) & 1 (ref) & 1 (ref) & 1 (ref) \\
\hline & Limited a little & 93.4 (93.3 to 93.4) & 1.02 (1.01 to 1.03$)$ & $1.12(1.11$ to 1.13$)$ & $1.08(1.07$ to 1.08$)$ \\
\hline \multirow{9}{*}{ Ethnicity } & Bangladeshi & 82.7 (82.0 to 83.4) & 3.26 (3.11 to 3.42$)$ & 3.48 (3.31 to 3.65$)$ & 2.56 (2.43 to 2.69 ) \\
\hline & Black African & 67.2 (66.6 to 67.8$)$ & 7.62 (7.40 to 7.84$)$ & 7.59 (7.37 to 7.81$)$ & 5.01 (4.86 to 5.16$)$ \\
\hline & Black Caribbean & 73.8 (73.4 to 74.2$)$ & 5.55 (5.44 to 5.66$)$ & 6.35 (6.22 to 6.47$)$ & 4.85 (4.75 to 4.96$)$ \\
\hline & Chinese & 82.8 (82.3 to 83.4$)$ & 3.23 (3.11 to 3.36$)$ & 3.11 (2.99 to 3.23$)$ & 2.64 (2.54 to 2.75 ) \\
\hline & Indian & $90.9(90.7$ to 91.0$)$ & 1.57 (1.54 to 1.60$)$ & 1.55 (1.52 to 1.59$)$ & $1.35(1.32$ to 1.38$)$ \\
\hline & Mixed & 85.3 (84.9 to 85.7$)$ & 2.69 (2.60 to 2.79 ) & 2.67 (2.58 to 2.77 ) & 2.21 (2.14 to 2.30$)$ \\
\hline & Other & 82.9 (82.6 to 83.2) & 3.22 (3.15 to 3.29$)$ & 3.12 (3.05 to 3.18$)$ & 2.44 (2.39 to 2.50$)$ \\
\hline & Pakistani & 79.6 (79.2 to 80.0 ) & 3.99 (3.89 to 4.09$)$ & 4.12 (4.02 to 4.22 ) & 3.59 (3.50 to 3.68 ) \\
\hline & White other & 87.7 (87.5 to 87.8$)$ & 2.20 (2.17 to 2.23$)$ & 2.24 (2.21 to 2.27$)$ & 1.93 (1.90 to 1.95$)$ \\
\hline \multirow{8}{*}{ Religion } & Buddhist & 84.1 (83.5 to 84.7$)$ & 2.88 (2.76 to 3.01$)$ & 2.63 (2.52 to 2.74$)$ & 2.03 (1.95 to 2.12$)$ \\
\hline & Hindu & 91.5 (91.2 to 91.7$)$ & 1.43 (1.39 to 1.47$)$ & 1.39 (1.35 to 1.43$)$ & $1.03(1.00$ to 1.06$)$ \\
\hline & Jewish & 93.1 (92.8 to 93.3) & 1.13 (1.09 to 1.18$)$ & 1.12 (1.08 to 1.17$)$ & 0.94 (0.90 to 0.97$)$ \\
\hline & Muslim & 79.1 (78.9 to 79.4$)$ & 4.02 (3.95 to 4.09$)$ & 4.04 (3.97 to 4.11$)$ & 2.74 (2.69 to 2.79$)$ \\
\hline & No religion & 91.9 (91.9 to 92.0$)$ & 1.34 (1.33 to 1.35$)$ & 1.25 (1.23 to 1.26$)$ & $1.23(1.22$ to 1.24$)$ \\
\hline & Other religion & 85.4 (84.9 to 85.8$)$ & $2.61(2.51$ to 2.71$)$ & 2.41 (2.32 to 2.50$)$ & 2.15 (2.07 to 2.23$)$ \\
\hline & $\begin{array}{l}\text { Religion not } \\
\text { stated }\end{array}$ & 91.5 (91.4 to 91.6$)$ & $1.42(1.41$ to 1.44$)$ & $1.40(1.38$ to 1.41$)$ & 1.35 (1.33 to 1.36$)$ \\
\hline & Sikh & 91.6 (91.3 to 91.9$)$ & 1.39 (1.34 to 1.45$)$ & $1.35(1.30$ to 1.41$)$ & $1.07(1.03$ to 1.11$)$ \\
\hline \multirow{4}{*}{$\begin{array}{l}\text { Household } \\
\text { tenure }\end{array}$} & Owned & 94.0 (93.9 to 94.0$)$ & 1 (ref) & 1 (ref) & 1 (ref) \\
\hline & Other & 91.1 (90.9 to 91.2) & $1.52(1.49$ to 1.55$)$ & 1.55 (1.52 to 1.58$)$ & 1.49 (1.46 to 1.52$)$ \\
\hline & Private rented & 88.4 (88.2 to 88.5$)$ & 2.05 (2.02 to 2.07 ) & 1.96 (1.94 to 1.99$)$ & 1.81 (1.79 to 1.83$)$ \\
\hline & Social rented & 89.9 (89.8 to 89.9$)$ & 1.75 (1.73 to 1.76$)$ & 1.77 (1.76 to 1.79$)$ & 1.60 (1.59 to 1.61$)$ \\
\hline \multirow[t]{2}{*}{ Rural-urban } & Rural & 94.5 (94.4 to 94.5$)$ & 1 (ref) & 1 (ref) & 1 (ref) \\
\hline & Urban & 92.8 (92.8 to 92.8$)$ & 1.33 (1.32 to 1.34$)$ & 1.34 (1.33 to 1.35$)$ & 1.12 (1.12 to 1.13$)$ \\
\hline
\end{tabular}


Table 3 Continued

\begin{tabular}{llllll}
\hline Exposure & Group & Vaccination rate & OR (model 1) & OR (model 2) & OR (model 3) \\
\hline Household & 2 elderly & $94.5(94.4$ to 94.5$)$ & 1 (ref) & 1 (ref) & 1 (ref) \\
composition & 1 elderly & $92.5(92.5$ to 92.6$)$ & $1.38(1.37$ to 1.39$)$ & $1.53(1.52$ to 1.54$)$ & $1.32(1.31$ to 1.33$)$ \\
& Care home & $94.9(94.8$ to 95.0$)$ & $0.92(0.89$ to 0.95$)$ & $1.10(1.06$ to 1.13$)$ & $0.89(0.86$ to 0.91$)$ \\
& Multigenerational & $90.3(90.3$ to 90.4$)$ & $1.83(1.82$ to 1.85$)$ & $1.77(1.76$ to 1.79$)$ & $1.39(1.38$ to 1.40$)$ \\
& Other (3+ adults) & $90.0(89.6$ to 90.3$)$ & $1.91(1.84$ to 1.97$)$ & $1.81(1.75$ to 1.88$)$ & $1.54(1.49$ to 1.60$)$ \\
\hline
\end{tabular}

Adults aged 70 years or over, living in England, alive on 15 March 2021. Model 1: unadjusted; model 2: adjusted for sex and age (cubic splines); model 3: adjusted for sex, age (cubic splines), care home status, rural/urban, region, ethnicity (except when looking at religion as an exposure), IMD quintile (except when looking at household tenure as an exposure), disability, BMI and comorbidities. See table 1 for more details on the variables included in the models.

BMI, body mass index; IMD, Index of Multiple Deprivation.

suggesting that geography, sociodemographic factors and pre-pandemic health only explain about $40 \%$ of the elevated odds of not being vaccinated.

Vaccination rates also varied markedly across religious groups. While $93.8 \%$ of Christians had been vaccinated, only $79.1 \%$ of Muslims and $84.1 \%$ of Buddhists had been vaccinated. Stark differences remained after adjustment for other factors, with an adjusted OR of not being vaccinated of 2.74 (2.69 to 2.79) for Muslims and 2.03 (1.95 to 2.12) for Buddhists, compared with Christians.

Greater area deprivation, less advantaged socioeconomic position (proxied by living in a rented home), being disabled and living either alone or in a multigenerational household were also associated with low vaccination rates, even when adjusting for other factors (table 3 ). These differences were less pronounced than the differences between ethnic groups or religious affiliations.

\section{DISCUSSION}

\section{Main findings}

Our analysis using whole population-level linked data in England suggests that first dose vaccination rates in adults aged $\geq 70$ years differed markedly by ethnic group and selfreported religious affiliation. The percentage of people vaccinated was lower among all minority ethnic groups compared with the white British population, with the lowest vaccination rates observed among Black African, Black Caribbean, Bangladeshi and Pakistani individuals. In addition, lower vaccination rates were reported among individuals who identified as Muslim and Buddhist. While some differences were found by deprivation, household factors, disability status and other sociodemographic factors, these were less pronounced compared with ethnicity or religious affiliation.

\section{Comparison with other studies}

Few studies have investigated how COVID-19 vaccination coverage varies by a wide range of sociodemographic characteristics. Our results on ethnicity and area deprivation are consistent with one previous study based on clinical records for $40 \%$ of patients in England. ${ }^{3}$ In addition, our results confirm studies showing that influenza, shingles and pneumococcal vaccination are patterned by similar factors, including ethnicity, deprivation and household size. ${ }^{8}$ Pre-pandemic, religion and culture have been postulated to be important factors in determining vaccination uptake ${ }^{9}$; our results extend this by showing that self-reported religious affiliation is an important factor in COVID-19 vaccine uptake. Differences in vaccination rate and potential vaccination hesitancy between religious groups may not be based on religious beliefs, but rather reflect safety and other concerns, ${ }^{10}$ or, given high infection rates in some of these groups, ${ }^{11}$ beliefs that vaccination is not needed after natural infection. We also find that vaccination rates vary by individual characteristics not reported in previous studies, such as household tenure (a proxy for socioeconomic status), household composition and disability status.

\section{Strengths and limitation}

The primary study strength is using nationwide linked population-level data from clinical records and the 2011 Census. Unlike studies based solely on electronic health records, we examined a wide range of sociodemographic characteristics. Unlike surveys, we can precisely estimate vaccination rates and ORs for small groups. The main limitation is that most demographic and socioeconomic characteristics are derived from the 2011 Census and therefore are 10 years old. However, we focus primarily on characteristics that are unlikely to change over time, such as ethnicity or religion, or likely to be stable for our population (adults aged $\geq 70$ years), such as household tenure. However, for the characteristics likely to change over time, such as disability status, the time difference may introduce some bias into the estimates, although this would be expected to dilute differences, since we are most likely missing some long-term health conditions. Care home residency and area deprivation were derived from the 2019 Patient Register and are therefore not subject to the same biases. Another limitation is that because the PHDA was based on the 2011 Census, it excluded people living in England in 2011 but not taking part in the 2011 Census; respondents who could not be linked to the 2011-2013 NHS Patient Register and recent 
migrants. Consequently, we excluded $5.4 \%$ of vaccinated people who could not be linked to the ONS PHDA.

\section{CONCLUSION}

There are stark differences in COVID-19 vaccination rates by ethnic group and religious affiliation. Research is now urgently needed to understand why these disparities exist in these groups and how they can best be addressed through public health policy and community engagement. Understanding barriers and supporting participation in the vaccine programme is especially important because the groups with low vaccination coverage were also at elevated risk of COVID-19 mortality in the first two waves of the pandemic, ${ }^{11-14}$ are associated with factors, such as frailty, that will continue to elevate risk as the pandemic evolves. ${ }^{15}$

\section{Author affiliations}

${ }^{1}$ Health Analysis and Life Event, Office for National Statistics, Newport, UK

${ }^{2}$ Faculty of Public Health, Environment and Society, London School of Hygiene \& Tropical Medicine, London, UK

${ }^{3}$ Diabetes Research Centre, University of Leicester, Leicester, UK

${ }^{4} \mathrm{NIHR}$ Leicester Biomedical Research Centre, University of Leicester, Leceister, UK

${ }^{5}$ University Hospitals of Leicester NHS Trust, Leicester, UK

${ }^{6}$ Methodology Division, Office for National Statistics, Newport, UK

${ }^{7}$ Nuffield Department of Medicine, University of Oxford, Oxford, UK

Acknowledgements We are grateful to Charlotte Bermingham for useful discussions about this paper.

Contributors Study conceptualisation was led by VN, TY and CR. VN, TY, CR, TD, $\mathrm{CHG}, \mathrm{SW}, \mathrm{DA}, \mathrm{MG}$ and KK contributed to the development of the research question, study design, with development of statistical aspects led by VN and TD. VN, JM and TD were involved in data specification, curation and collection. VN and TD conducted and checked the statistical analyses. VN, TY, CR, TD, CHG, JM, SW, DA, $M G$ and KK contributed to the interpretation of the results. VN, TY and CR wrote the first draft of the paper. VN, TY, CR, TD, CHG, JM, SW, DA, MG and KK contributed to the critical revision of the manuscript for important intellectual content and approved the final version of the manuscript. VN had full access to all data in the study and takes responsibility for the integrity of the data and the accuracy of the data analysis. The lead author (VN) affirms that the manuscript is an honest, accurate, and transparent account of the study being reported; that no important aspects of the study have been omitted; and that any discrepancies from the study as planned have been explained.

Funding This work was supported by a grant from the UKRI (MRC)-DHSC (NIHR) COVID-19 Rapid Response Rolling Call (MR/N020536/1) and from HDR-UK (HDRUK2020.138). KK, TY and CR are supported by the National Institute for Health Research (NIHR) Applied Research Collaboration East Midlands (ARC EM) and the NIHR Leicester Biomedical Research Centre (BRC). SW is an NIHR Senior Investigator and is supported by the NIHR Health Protection Research Unit in Healthcare Associated Infections and Antimicrobial Resistance at Oxford University in partnership with Public Health England (PHE) (NIHR200915) and the NIHR BRC, Oxford.

Disclaimer The views expressed in this publication are those of the authors and not necessarily those of the ONS, the NHS, the NIHR, the Department of Health or PHE.

Competing interests KK is Director of the University of Leicester Centre for Black Minority Ethnic Health, Trustee of the South Asian Health Foundation, Chair of the Ethnicity Subgroup of SAGE and Member of Independent SAGE.

Patient and public involvement Patients and/or the public were not involved in the design, or conduct, or reporting, or dissemination plans of this research.
Patient consent for publication Not required.

Ethics approval Ethical approval was obtained from the National Statistician's Data Ethics Advisory Committee (NSDEC(20)12).

Provenance and peer review Not commissioned; externally peer reviewed.

Data availability statement Data are not yet available, but will be made available on the ONS Secure Research Service for accredited researchers.

Open access This is an open access article distributed in accordance with the Creative Commons Attribution 4.0 Unported (CC BY 4.0) license, which permits others to copy, redistribute, remix, transform and build upon this work for any purpose, provided the original work is properly cited, a link to the licence is given, and indication of whether changes were made. See: https://creativecommons.org/ licenses/by/4.0/.

\section{ORCID iDs}

Vahe Nafilyan http://orcid.org/0000-0003-0160-217X

Charlotte Hannah Gaughan http://orcid.org/0000-0002-3349-3062

\section{REFERENCES}

1 UK Coronavirus Dashboard. Coronavirus (COVID-19) in the UK - vaccinations, 2021. Available: https://coronavirus.data.gov.uk/ details/vaccinations

2 Pebody RG, Hippisley-Cox J, Harcourt S, et al. Uptake of pneumococcal polysaccharide vaccine in at-risk populations in England and Wales 1999-2005. Epidemiol Infect 2008;136:360-9.

3 Spencer AM, Roberts SA, Brabin L, et al. Sociodemographic factors predicting mother's cervical screening and daughter's HPV vaccination uptake. J Epidemiol Community Health 2014;68:571-7.

4 Hungerford D, Macpherson P, Farmer S, et al. Effect of socioeconomic deprivation on uptake of measles, mumps and rubella vaccination in Liverpool, UK over 16 years: a longitudinal ecological study. Epidemiol Infect 2016;144:1201-11.

5 MacKenna B, Curtis HJ, Morton CE. Trends, regional variation, and clinical characteristics of COVID-19 vaccine recipients: a retrospective cohort study in 23.4 million patients using OpenSAFELY. medRxiv 2021.

6 Department for Communities and Local Government,. The English indices of deprivation 2015, 2015. Available: https://www.gov.uk/ government/statistics/english-indices-of-deprivation-2015

7 Clift AK, Coupland CAC, Keogh $\mathrm{RH}$, et al. Living risk prediction algorithm (QCOVID) for risk of hospital admission and mortality from coronavirus 19 in adults: national derivation and validation cohort study. BMJ 2020;371:m3731.

8 Tan PS, Patone M, Clift AK. Influenza, shingles and pneumococcal vaccine uptake, offer and refusal in adult populations at high-risk for COVID-19: a UK population-based cohort study. SSRN Electronic Journal 2021.

9 Lane S, MacDonald NE, Marti M, et al. Vaccine hesitancy around the globe: analysis of three years of WHO/UNICEF joint reporting form data-2015-2017. Vaccine 2018;36:3861-7.

10 Grabenstein JD. What the world's religions teach, applied to vaccines and immune globulins. Vaccine 2013;31:2011-23.

11 Gaughan $\mathrm{CH}$, Ayoubkhani D, Nafilyan V, et al. Religious affiliation and COVID-19-related mortality: a retrospective cohort study of prelockdown and postlockdown risks in England and Wales. J Epidemiol Community Health 2021. doi:10.1136/jech-2020-215694. [Epub ahead of print: 06 Jan 2021].

12 Ayoubkhani D, Nafilyan V, White C, et al. Ethnic-minority groups in England and Wales-factors associated with the size and timing of elevated COVID-19 mortality: a retrospective cohort study linking census and death records. Int J Epidemiol 2021;49:1951-62.

13 Mathur R, Rentsch CT, Morton CE. Ethnic differences in COVID-19 infection, hospitalisation, and mortality: an OpenSAFELY analysis of 17 million adults in England. medRxiv 2020:2020.09.22.20198754.

14 Nafilyan V, Islam N, Mathur R, et al. Ethnic differences in COVID-19 mortality during the first two waves of the coronavirus pandemic: a nationwide cohort study of 29 million adults in England. Eur $J$ Epidemiol 2021. doi:10.1007/s10654-021-00765-1. [Epub ahead of print: 16 Jun 2021].

15 Palermo S. Covid-19 pandemic: maximizing future vaccination treatments considering aging and frailty. Front Med 2020;7:632. 